\title{
Variability of clinical characteristic of colorectal cancer patients - analysis of selected parameters
}

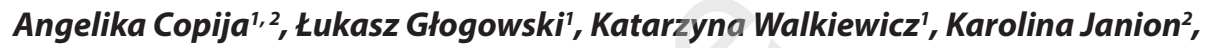 \\ Ewa Nowakowska-Zajdel ${ }^{1,2}$ \\ 'Department of Clinical Oncology, Regional Specialised Hospital No. 4 in Bytom \\ ${ }^{2}$ Department of Nutrition Related Disease Prevention, School of Public Health in Bytom, \\ Medical University of Silesia, Katowice, Poland
}

\section{Correspondence: \\ Angelika Copija \\ Department of Clinical Oncology, \\ Regional Specialised Hospital \\ No. 4 in Bytom \\ 41-900 Bytom, al. Legionów 10 \\ e-mail:ang.c@wp.pl \\ Received: \\ 16.08.2018 \\ Accepted: \\ 29.08.2018 \\ DOI: 10.24292/01.OR.290818 Copyright $\odot$ Medical Education. All rights reserved.}

\section{ABSTRACT}

Introduction: A steady increase of the incidence of colorectal cancer has been observed for over 30 years, particularly in well-developed countries. Colorectal cancer is one of the lifestyle-related neoplasms and depends on environmental factors.

Aim: Aim of the study was to analyse selected clinical features of colorectal cancer patients.

Material and methods: The study group consisted of 577 consecutive patients with colorectal cancer treated in the Department of Clinical Oncology in Bytom in 2006-2014. The patients were included into the study prospectively. The analysis of selected clinical, pathological and anthropometrical parameters was conducted.

Results: The study group included 237 women and 341 men aged 26 to 86 years (mean age $64.3 \pm 9.2$ years). Primary tumours were mostly located in the colon and had histological grade 2 . The surgical removal of the primary tumour was performed in 540 patients. 65 patients underwent preoperative radiotherapy, 201 - postoperative chemotherapy and 91 - postoperative radio-chemotherapy. 132 of patients obtained the first-line palliative chemotherapy. 88 of patients did not received oncological treatment. KRAS/RAS mutation were determined in 73 patients and the EGFR expression status in 53 patients.

Conclusions: Colorectal cancer patients are a heterogeneous group with differential clinical, pathological and molecular features.

1. Therapeutic management of patients with colorectal cancer largely depends on its location, clinical and pathological stage, patients performance status and comorbidities.

2. Understanding the clinical features of patients with colorectal cancer becomes helpful in designing of screening, which take into account clinical profile of the patient, i.e. age, gender, comorbidities and anthropometric characteristics.

Key words: colorectal cancer, clinical features, epidemiology 


\section{INTRODUCTION}

Colorectal cancer (colorectal cancer) is one of the most frequent malignancies in the developed countries. The incidence of colorectal cancer in Poland has increased 4-fold in men and 3 -fold in women during the last 35 years [1]. In 2015, colorectal cancer was the third most common malignancy in polish females (after breast and lung cancer) and in males (after lung and prostate cancer) [2]. The incidence of colon cancer is more frequent than rectal cancer. In Polish population in 2015, colon cancer represented $7.0 \%$ of new registered cancer in males and $6.2 \%$ in females, while rectal cancer $4.4 \%$ and $2.8 \%$ respectively [2]. Furthermore, colorectal cancer was the third cause of cancer-related deaths in women (11.3\%) after lung cancer and breast cancer and the second cause in men (11.2\%) after lung cancer [2].

In Europe, colorectal cancer is the most common malignancy. The incidence has increased from 376000 in 2004 to 471000 in 2012. Colorectal cancer is responsible for $12.3 \%$ of deaths from malignant neoplasms in Europe, taking the second position after lung cancer [3]. According to estimates of mortality for selected malignancies in six EU countries (France, Germany, Italy, Poland, Spain, United Kingdom) for 2018, the expected standardized mortality rate for colorectal cancer in Poland is the highest among the surveyed European countries $(20 / 100,000)$ [4].

Tumours of the colorectal tract are a heterogeneous group varying in the clinical and molecular characteristic. The recommendations for the therapeutic management differs significantly between colon and rectum cancer. The right and left site of colon differ in terms of embryologic processes, microenvironmental and anatomical aspects, i.e. blood supply [5].

The pathogenesis of colorectal cancer is multidimensional. Most of colorectal cancer cases are sporadic and are determined by many factors. Approximately $10-15 \%$ of tumours are familial, related to i.e. Lynch syndrome and familial adenomatous polyposis (FAP) [4]. About $10-15 \%$ of patients with colorectal cancer have a family tendency unrelated to the aforementioned syndromes, defined as familial colorectal cancer (FCC) $[6,7]$. Family occurring colorectal cancer is usually unidentified and not clinically important.

A number of risk factors for colorectal cancer were identified, including environmental, nutritional, genetic factors and the precancerous conditions. Environmental factors include i.a. age over 40 years, family history of colorectal cancer, endometrial cancer, breast, ovarian or prostate cancer. The increased risk of colorectal cancer is observed for people who are overweight, burdened with insulin resistance, diabetes and metabolic syndrome, as well as for the physical inactive persons and smokers. The confirmed risk factors are low-fibre diet rich in animal fats and red meat. Increased incidence of colorectal cancer is also indicated among patients diagnosed with inflammatory bowel diseases (Crohn's disease and ulcerative colitis) and previously treated for colorectal cancer. The risk increases with age and the highest incidence is observed around the age of 70 years. The increasing incidence of colorectal cancer in people younger than 50 has been observed in recent years [8-11], wherein the trend has been noted mainly in developed countries. The percentage of colorectal cancer cases diagnosed before the age of 50 in developed countries is $11-18 \%$, and the growth rate of colorectal cancer diagnoses in this age group is higher than the overall increase in incidence in the general population [12].

Due to the high prevalence and good effect of treatment of early-diagnosed disease, colorectal cancer may be detected by screening programs. The best documented examinations associated with the decrease in mortality caused by colorectal cancer is colonoscopy and the faecal occult blood test. According to the ESMO recommendation, the faecal occult blood test should be performed once a year. On the other hand, NCCN recommends colonoscopy performed every 10 years as the only screening test $[13,14]$. The results of a randomized clinical trial demonstrated that screening with the occult blood test reduces the risk of death from colorectal cancer by $25 \%$. The effectiveness of colonoscopy as a screening test has been confirmed by Polish researchers in the study of more than 50 thousand people $[15,16]$.

Despite the fact that the risk factors for colorectal cancer are relatively well-known, the group of people who should be subject to more intensive screening has not been determined yet. The previous recommendations of international organizations are similar - it is widely accepted that screening (regardless of the method chosen) is carried in the group of people aged 50 to 65 years old, and in the case of family history of colorectal cancer - over the age of 40 . Poland is one of four European countries, along with Germany, Italy and Luxembourg, where the program of colorectal cancer early detection is carried by colonoscopy [17].

The observed increase in the incidence of colorectal cancer leads to seeking of new treatment methods that may improve survival rates. It is essential to introduce both screening strategies, in order to improve the detection and implementation of early medical intervention, and the education and health promotion to exclude colorectal cancer risk factors. Distinction of risk groups associated with increased incidence of colorectal 
cancer allows the successful planning of screening, and implementation of oncological vigilance and supervision in everyday medical practice.

\section{AIM OF THE STUDY}

Aim of the study was the analysis of clinical features of consecutive patients with colorectal cancer treated in the Department of Clinical Oncology in the years 2006-2014.

\section{MATERIAL AND METHODS}

The study group included 577 patients with colorectal cancer treated in the Department of Clinical Oncology of the Regional Specialised Hospital No. 4 in Bytom in the years 2006-2014. In all patients, the diagnosis of colorectal cancer was confirmed histologically on the basis of the tissue samples collected during colonoscopy and/or surgery. Patients were included into the study group prospectively, after initial visit in the Oncology Clinic or after the first admission to the Department of Clinical Oncology. The analysis of selected clinical, pathological and anthropometrical parameters was conducted. The data were analysed according to the location of the primary tumour (colon or rectum).

The considered data included: age at time of diagnosis, gender, weight, height and body mass index, the location of the primary tumour (colon, rectum), tumour histological grade, TNM stage according to the UICC/AJCC 2010 recommendation, the course of oncological treatment (radical treatment, palliative treatment or observation), haematological and biochemical parameters of blood and patients' comorbidities.

Medical history, anthropometric parameters and laboratory tests were assessed prior to oncological treatment implementation. The location of the primary tumour was based on the description of colonoscopy or surgical protocol. According to the current Polish Society of Clinical Oncology (PTOK), the rectal location was defined as tumours located in the section of the large intestine to a height of $15 \mathrm{~cm}$ from the anal verge.

Clinical stage was assessed on the basis of the report of histopathological examination and imaging studies. Histological grade $(\mathrm{G} 1-\mathrm{G} 3, \mathrm{Gx})$ was determined by the pathomorphologist using routine testing of the samples collected during colonoscopy or surgery.

\section{RESULTS}

The study group included 237 (41\%) women and 341 (59\%) men aged 26 to 86 years (mean age $64.3 \pm 9.2$ ). The young patients, aged under 50 , accounted for $10 \%$ all patients $(n=58) .139$ patients (24\%) were over 70 years old. The age distribution in the whole study group is presented in figure 1 . The average age at diagnosis was 62.6 years in women (34.8-86.2 years) and 63.2 years among men (26.2-83.9 years). This difference is not statistically significant $(p=0.49)$.

FIGURE 1.

Age distribution in the study group.

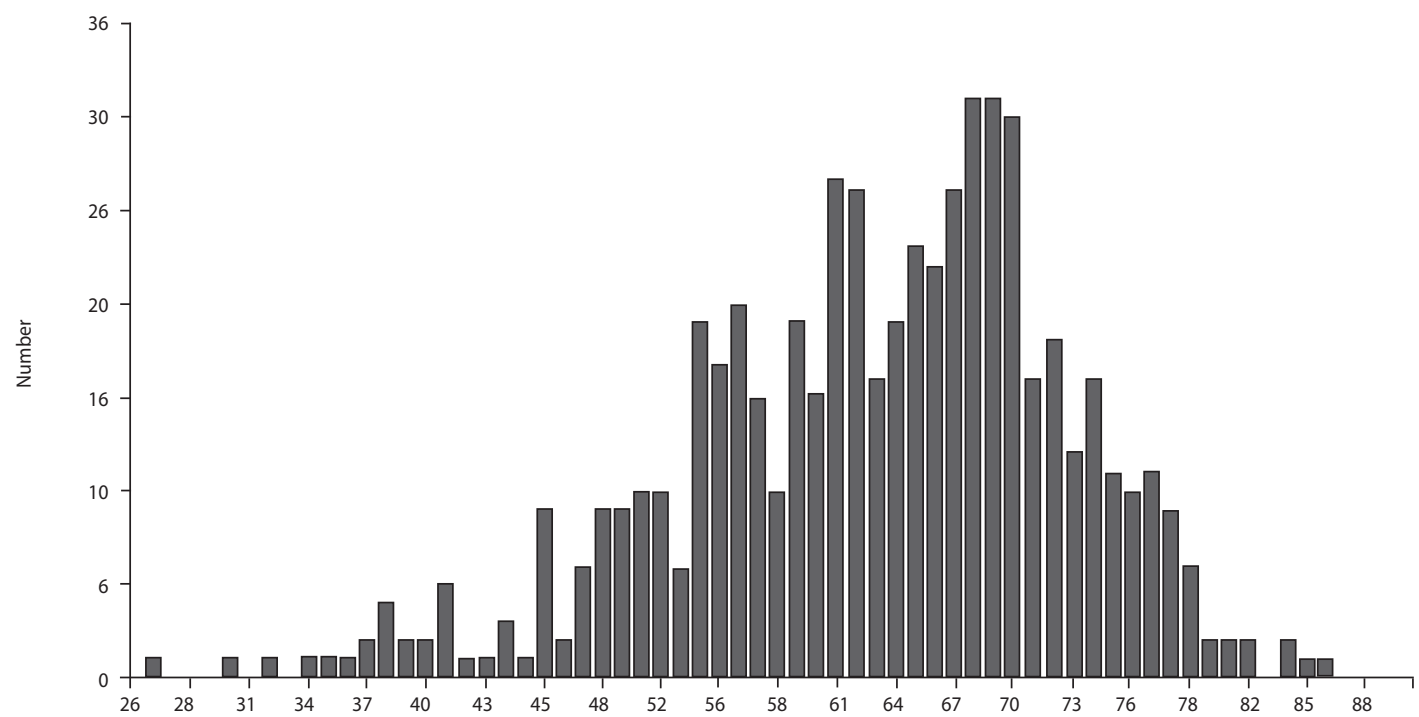


The primary tumour was located in the colon in $60 \%$ of patients. Colorectal cancer was the most commonly diagnosed in stage III and $60.3 \%$ of tumours were graded as 2 (G2).

The data on the primary tumour location, clinical stage, histological grade and of the implemented treatment are presented in table 1.

The surgical removal of the primary tumour was performed in 540 patients. The other patients underwent laparotomy without tumour removal or were not scheduled for surgery due to previously identified distant metastases and no evidence of bowel obstruction. 65 patients underwent preoperative radiotherapy, 201 - postoperative chemotherapy and 91 - postoperative radio-chemotherapy. 132 of patients obtained the first-line palliative chemotherapy. 88 of patients did not received oncological treatment, including patients who did not require adjuvant treatment due to the low disease advancement (72 patients; all patients with clinical stage I and some of patients with stage II) or patients not qualified for oncological treatment due to the unsatisfactory condition.
The assessment of KRAS/RAS mutation and the expression of membrane receptor for epidermal growth factor (EGFR) was evaluated in the group of selected patients using the tissue samples collected from the primary tumour. KRAS/RAS mutation were determined in 73 patients and the EGFR expression status - in 53 patients. Characteristics of the subgroup with the known RAS status is presented in table 2.

\section{DISCUSSION}

Therapeutic management of patients with colorectal cancer largely depends on its location and clinical and pathological stage. The differences in treatment of patients with colon and rectal cancer are a result of many factors, i.e. linked with embryologic development of colorectal tract and anatomical aspects conditioning treatment options.

Our results indicate that the average age of onset in the study group is around 65 years, which is confirmed by numerous epidemiological studies conducted in Poland and around the world $[2,18]$. The largest group of 577 patients are individuals aged

TABLE 1.

Characteristics of the study group.

\begin{tabular}{|c|c|c|c|c|}
\hline & & $\begin{array}{l}\text { All patients } \\
(\mathrm{n}=577)\end{array}$ & Women $(n=237)$ & Men $(n=340)$ \\
\hline \multirow{2}{*}{ Primary tumour location } & Colon & 346 & 156 & 190 \\
\hline & Rectum & 231 & 81 & 150 \\
\hline \multirow{4}{*}{ Histopathological grade } & G1 & 62 & 23 & 38 \\
\hline & G2 & 348 & 132 & 216 \\
\hline & G3 & 85 & 44 & 41 \\
\hline & Gx & 82 & 38 & 42 \\
\hline \multirow{4}{*}{$\begin{array}{l}\text { Clinical stage according to UICC } \\
\text { guidelines } 2010\end{array}$} & I & 62 & 27 & 34 \\
\hline & $\|A-\| C$ & 152 & 59 & 92 \\
\hline & IIIA-IIIC & 220 & 95 & 125 \\
\hline & IVA-IVB & 143 & 56 & 89 \\
\hline \multirow{3}{*}{ Type of oncological treatment } & Curative treatment & 357 & 161 & 214 \\
\hline & Palliative treatment & 132 & 60 & 77 \\
\hline & Observation & 88 & 42 & 49 \\
\hline
\end{tabular}

TABLE 2.

Characteristics of patients with known RAS status.

\begin{tabular}{|c|c|c|c|}
\hline \multicolumn{2}{|c|}{ Feature } & $\begin{array}{c}\text { Wild-type RAS } \\
(\mathbf{n}=50)\end{array}$ & Mutant RAS (n=23) \\
\hline \multirow{2}{*}{ Gender } & Women & 20 & 9 \\
\cline { 2 - 4 } & Men & 30 & 14 \\
\hline \multirow{2}{*}{ Primary tumour location } & Colon & 27 & 10 \\
\cline { 2 - 4 } & Rectum & 23 & 2 \\
\hline \multirow{3}{*}{ Clinical stage according to UICC 2010 } & I & 2 & 2 \\
\cline { 2 - 4 } & IIA-IIC & 6 & 8 \\
\cline { 2 - 4 } & IIIA-IIIC & 12 & 11 \\
\cline { 2 - 4 } & IVA-IVB & 30 & 2 \\
\hline
\end{tabular}


61-70 years ( 235 patients, 89 women and 145 men). The second largest group are patients aged 51-60 years, the third one - over the age of 70 years. Patients under 50 years old represented $10 \%$ of the study group. Other authors confirm that the percentage of patients under 50 years of age is about $10 \%$, and in the study carried by Schellerer et al. up to $12.4 \%$ in the whole group [19].

Colorectal cancer is the most often diagnosed in clinical stage III, which is associated with worse prognosis at the moment of diagnosis. In analysed population, $40 \%$ of women and $36.8 \%$ of men were diagnosed with colorectal cancer in stage III. They were the largest group. Similarly, in the study conducted by Chinese authors, colorectal cancer was most frequent diagnosed in stage III [20]. In European countries, Dukes' $\mathrm{C}$ colorectal cancer is diagnosed in $11 \%$ of patients, and Dukes' D - in $21 \%$. The opposite results are noted in the US, where the Dukes' $\mathrm{C}$ tumours are diagnosed in $21 \%$ patients and Dukes' D - in $11 \%$. This favourable tumours profile is associated with better outcome in these countries [18]

RAS gene status was determined in 73 patients in the study group. Determination of the status of RAS and EGFR gene was not a routine procedure - it is required in clinical practice before the qualification for treatment with panitumumab or cetuximab. KRAS mutation was found in 23 patients (31\%). This incidence is similar with data for the Polish population - 40\% [21]. RAS mutation is an unfavourable prognostic factor in colorectal cancer. Tumours with RAS gene mutation have more aggressive clinical course and are often associated with the resistance to traditional chemotherapy regimens [22].

\section{CONCLUSIONS}

1. Colorectal cancer patients are a heterogeneous group with differential clinical, pathological and molecular features.

2. Therapeutic management of patients with colorectal cancer largely depends on its location, clinical and pathological features.

3. Understanding the clinical features of patients with colorectal cancer becomes helpful in designing of screening, which take into account clinical profile of the patient, i.e. age, gender, comorbidities and anthropometric characteristics.

\section{References}

1. Wyrwicz L, Wysocki P, Zyśk R. Rak jelita grubego - społeczne znaczenia zmian w zakresie epidemiologii i możliwości leczenia w Polsce. Obywatelskie Porozumienia na Rzecz Onkologii, Warszawa 2014.

2. Didkowska J, Wojciechowska U. Nowotwory złośliwe w Polsce w 2015 roku. Centrum Onkologii, Warszawa 2017.

3. Ferlay J. Cancer incidence and mortality worldwide: sources, methods and major patterns in GLOBOCAN 2012. Int J Cancer 2014; 136: 359-386.

4. Malvezzi M, Carioli G, Bertuccio P et al. European cancer mortality predictions for the year 2018 with focus on colorectal cancer. Ann Oncol 2018; 29(4): 1016-1022.

5. Brulé SY, Jonker DJ, Karapetis CS et al. Location of colon cancer (right-sided versus left-sided) as a prognostic factor and a predictor of benefit from cetuximab in NCIC CO.17. Eur J Cancer 2015; 51: 1405-1414.

6. Mesher D, Dove-Edwin I, Sasieni P et al. A pooled analysis of the outcome of prospective colonoscopic surveillance for familial colorectal cancer. Int J Cancer 2014; 134: 939-947.

7. Johnson V, Lipton LR, Cummings $C$ et al. Analysis of somatic molecular changes, clinicopathological features, family history, and germline mutations in colorectal cancer families. evidence for efficient diagnosis of HNPCC and for the existence of distinct groups of non-HNPCC families. J Med Gen 2005; 42: 756-762.

8. Austin $\mathrm{H}$, Henley $\mathrm{SJ}$, King J et al. Changes in colorectal cancer incidence rates in young and older adults in the United States. what does it tell us about screening. Cancer Causes Control 2014; 25: 191-201.

9. Singh PN, Fraser GE. Dietary risk factors for colon cancer in a low-risk population. Am J Epidemiol 1998; 148: 761-774.

10. Inra JA, Syngal S. Colorectal cancer in young adults. Dig Dis Sci 2015; 60: 722-733.

11. Bailey CE, Hu CY, You YN et al. Increasing disparities in the age-related incidences of colon and rectal cancers in the United States, 1975-2010. JAMA Surg 2015; 150: 17-22.

12. Meyer JE, Narang T, Schnoll-Sussman FH et al. Increasing incidence of rectal cancer in patients aged younger than 40 years: an analysis of the surveillance, epidemiology, and end results database. Cancer 2010; 116: 4354-4359.

13. [online: www.esmo.org/Guidelines/Gastrointestinal-Cancers/Early-Colon-Cancer].

14. [online: www.nccn.org/professionals/physician_gls/f_guidelines.asp\#colorectal_screening].

15. Kaminski MF, Kraszewska E, Rupinski M et al. Design of the Polish Colonoscopy Screening Program: a randomized health services study. Endoscopy 2015; 47: 1144-1150.

16. Regula J, Rupinski M, Kraszewska E et al. Colonoscopy in colorectal cancer screeening for detection of advanced neoplasia. New Engl J Med 2006; 355: 1863-1872. 
17. [online: www.mz.gov.pl/zdrowie-i-profilaktyka/programy-zdrowotne/wykaz-programow/narodowy-program-zwalczania-chorob-nowotworowych].

18. Allemani C, Rachet B, Weir HK et al. Colorectal cancer survival in the USA and Europe: a CONCORD high-resolution study. BMJ Open 2013; 3(9): e003055.

19. Schellerer VS, Merkel S, Schumann SC et al. Despite aggressive histopathology survival is not impaired in young patients with colorectal cancer. Int J Colorectal Dis 2012; 27: 71-79.

20. Yusup A, Wang HJ, Rahmutula A et al. Clinical features and prognosis in colorectal cancer patients with different ethnicities in Northwest China. World J Gastroenterol 2013; 19: 7183-7188.

21. Krzakowski M, Warzocha K (ed). Zalecenia postępowania diagnostyczno-terapeutycznego w nowotworach złośliwych 2013. Via Medica, Gdańsk 2013: 179-203.

22. Vincenzi B, Cremolini C, Sartore-Bianchi A et al. Prognostic significance of K-Ras mutation rate in metastatic colorectal cancer patients. Oncotarget 2015; 6: 31604-31612.

Authors' contributions: Angelika Copija: the theme and concept of the work, creating the database, preparing the manuscript; Łukasz Głogowski: the theme and concept of the work, creating the database, preparing the manuscript; Katarzyna Walkiewicz: creating the database, gathering and interpretation of the literature; Karolina Janion: creating the database, gathering and interpretation of the literature; Ewa Nowakowska-Zajdel: the theme and concept of the work, analysis of the literature, and revision of the article content.

Conflict of interests: None.

Financial support: None. Ethics:

The paper complies with the Helsinki Declaration, EU Directives and harmonized requirements for biomedical journals. 